\title{
EPIDEMIAS POR ENFERMEDADES INFECTO-CONTAGIOSAS EN EL CINE MEXICANO (1922-2019)
}

\section{Infecto-contagious disease epidemics in Mexican cinema (1922-2019)}

\author{
Rocío Betzabeé GONZÁLEZ DE ARCE ARZAVE; Julieta Eloisa GONZÁLEZ DE ARCE ARZAVE² \\ ${ }^{1}$ Doctorado en Humanidades, Universidad Autónoma Metropolitana, Unidad Xochimilco. Ciudad de México \\ (México). ${ }^{2} \mathrm{Hospital}$ General Regional No.1 Carlos MacGregor Sánchez Navarro. Ciudad de México (México). \\ Correo electrónico: chioglezarce@hotmail.com; tnekrjworld@hotmail.com
}

Recibido: 31 de diciembre de 2020

Aceptado: 16 de enero de 2021

\section{Resumen}

El presente artículo hace una revisión de 36 producciones o coproducciones mexicanas estrenadas entre 1922 y 2019 en que aparecen, como parte de la trama, epidemias por enfermedades infecto-contagiosas. Dicha revisión permitió detectar en la filmografía mexicana la presencia de 15 enfermedades epidémicas de este tipo: tuberculosis, viruela, sarampión, paludismo, influenza española, oncocercosis, poliomielitis, fiebres negras, difteria, peste negra, fiebre tifoidea, meningitis cerebroespinal epidémica, rabia, sida y una gripa viral desconocida. El texto se detiene en algunas secuencias clave de estas películas y analiza la manera en que estas enfermedades aparecen en el cine mexicano como alegorías que reflexionan sobre el orden social y que expresan los temores e inquietudes colectivos de un cierto momento histórico.

Palabras clave: enfermedades infecto-contagiosas; epidemias; cine mexicano; México.

\begin{abstract}
This article reviews 36 Mexican productions or co-productions released between 1922 and 2019 in which they appear, as part of the plot, epidemics due to infectio-contagious diseases. This survey made it possible to detect in Mexican cinema the presence of 15 epidemic diseases of this type: tuberculosis, smallpox, measles, malaria, Spanish influenza, onchocerciasis, poliomyelitis, black fever, diphtheria, black plague, typhoid fever, epidemic cerebrospinal meningitis, rabies, AIDS and an unknown viral flu. The text examines some of the key sequences from these films, and
\end{abstract}


analyzes the way in which these diseases appear in Mexican cinema as allegories that reflect on the social order and that express the collective fears and concerns of a certain historical moment.

Keywords: infecto-contagious diseases; epidemics; Mexican cinema; Mexico.

\section{Introducción}

El cine, como producto cultural, puede considerarse una fuente secundaria de información en la medida en que en las películas cristalizan los temores, las preocupaciones y las esperanzas de las sociedades, esto es, los imaginarios colectivos que configuran las formas de pensar y las mentalidades. En ese sentido, la revisión de la producción cinematográfica mexicana que en este artículo se hace permitió no sólo dar cuenta de las múltiples epidemias infecto-contagiosas que afectaron a México durante el siglo XX y las primeras décadas del siglo XXI, sino aproximarse a la manera en que estas epidemias se configuraron como sistemas de metáforas, es decir, como alegorías de las aprensiones e inquietudes sociales de una época pues, como plantea Susan Sontag, "la imaginería patológica sirve para expresar una preocupación por el orden social"1.

El texto se organiza alrededor de las 15 enfermedades infecto-contagiosas que aparecen en 36 producciones o coproducciones mexicanas estrenadas entre 1922 y 2019, las cuales se ennumeran en la tabla 1. Cada película se glosa brevemente y se comenta en términos de las alegorías que construye en torno a la enfermedad. En algunos casos el artículo se detiene en secuencias clave, que se analizan a mayor profundidad.

\section{Tuberculosis}

La tuberculosis es la primera enfermedad infecto-contagiosa que hemos podido registrar en la cinematografía mexicana. Se trata de una bacteriosis que puede afectar todos los órganos del cuerpo, pero que se manifiesta más comúnmente en los pulmones. Entre los síntomas que producen las micobacterias del complejo Mycobacterium tuberculosis destacan la tos, la fiebre, los sudores nocturnos y la pérdida de peso², sintomatología que desarrollan las protagonistas de las dos versiones fílmicas de la novela La dama de las camelias del escritor francés Alexandre Dumas (hijo): La dama de las camelias (1922) de Carlos Stahl y La dama de las camelias (1944) de Gabriel Soria. Herederas de la tradición decimonónica romántica, estas adaptaciones presentan la historia de mujeres de moral "disipada" que tras una vida "licenciosa" contraen tuberculosis y mueren. La enfermedad se constituye en estos filmes en una metáfora de la corrupción moral de los personajes.

Un buen número de mujeres del cine mexicano dieron continuidad a esta tradición en que la enfermedad, por un lado, visibiliza corporalmente la condición moral viciada del personaje y es, por otro, el vehículo para la expiación de las culpas. Caridad la protagonista de Mulata (1954) de Gilberto Martínez Solares, película basada en la novela Mulatilla, estampa negra de Roberto Olivencia Márquez, muere tosiendo en brazos de su amado muy probablemente de tuberculosis, padecimiento que condena a muerte a Satin, la amiga prostituta de la protagonista de Naná (1985) de Rafael Baledón, José Bolaños e Irma Serrano en la película homónima a la novela de Emilio Zolá. Pero no solo las mujeres enferman de tuberculosis en el cine mexicano. En A la sombra del puente (1948) de Roberto Gavaldón es un ex-presidiario quien desarrolla la enfermedad que resulta, aquí, signo inequívoco de su pasado criminal; y en El rebozo de soledad (1952) de Roberto Gavaldón son los niños de un pueblo apartado de la ciudad capital los que contraen tuberculosis intestinal por tomar la leche de las vacas enfermas del cacique David Acosta, quien se niega a sacrificar a los animales en beneficio de la colectividad. En este último caso, la 


\section{EPIDEMIAS POR ENFERMEDADES INFECTO-CONTAGIOSAS EN EL CINE MEXICANO (1922-2019)}

ROCío BETZABEÉ GONZÁLEZ DE ARCE ARZAVE; JULIETA ELOISA GONZÁLEZ DE ARCE ARZAVE

Tabla 1. Películas seleccionadas

\begin{tabular}{|c|c|c|}
\hline Título19, 20, 21 & Año / País / Director19, 20, 21 & Enlace IMDb \\
\hline A la sombra del puente & $\begin{array}{l}1948 \\
\text { México } \\
\text { Roberto Gavaldón }\end{array}$ & $\begin{array}{l}\text { https://www.imdb.com/title/ } \\
\text { tt0243738/?ref_=fn_al_tt_1 }\end{array}$ \\
\hline Amor que mata & $\begin{array}{l}1994 \\
\text { México } \\
\text { Valentín Trujillo }\end{array}$ & $\begin{array}{l}\text { https://www.imdb.com/title/ } \\
\text { tt0318984/ }\end{array}$ \\
\hline As negro & $\begin{array}{l}1954 \\
\text { México } \\
\text { Fernando Méndez }\end{array}$ & $\begin{array}{l}\text { https://www.imdb.com/title/ } \\
\text { tt0252905/?ref_=fn_al_tt_1 }\end{array}$ \\
\hline Bienvenido-Welcome & $\begin{array}{l}1995 \\
\text { México } \\
\text { Gabriel Retes }\end{array}$ & $\begin{array}{l}\text { https://www.imdb.com/title/ } \\
\text { tt0109265/?ref_=nv_sr_srsg_0 }\end{array}$ \\
\hline Casos de Alarma 1 (SIDA) & $\begin{array}{l}1989 \\
\text { México } \\
\text { Benjamín Escamilla }\end{array}$ & $\begin{array}{l}\text { https://www.imdb.com/title/ } \\
\text { tt0319148/?ref_=fn_al_tt_1 }\end{array}$ \\
\hline $\begin{array}{l}\text { Del odio nace el amor (The Torch / } \\
\text { Beloved) }\end{array}$ & $\begin{array}{l}1951 \\
\text { México, Estados Unidos } \\
\text { Emilio Fernández }\end{array}$ & $\begin{array}{l}\text { https://www.imdb.com/title/ } \\
\text { tt0041971/?ref_=nv_sr_srsg_0 }\end{array}$ \\
\hline El año de la peste & $\begin{array}{l}1980 \\
\text { México } \\
\text { Felipe Cazals }\end{array}$ & $\begin{array}{l}\text { https://www.imdb.com/title/ } \\
\text { tt0077195/?ref_=fn_al_tt_1 }\end{array}$ \\
\hline El hubiera si existe & $\begin{array}{l}2019 \\
\text { México } \\
\text { Luis Eduardo Reyes }\end{array}$ & $\begin{array}{l}\text { https://www.imdb.com/title/ } \\
\text { tt6992642/?ref_=fn_al_tt_1 }\end{array}$ \\
\hline El mal (The Rage) & $\begin{array}{l}1967 \\
\text { México, Estados Unidos } \\
\text { Gilberto Gazcón }\end{array}$ & $\begin{array}{l}\text { https://www.imdb.com/title/ } \\
\text { tt0060882/?ref_=fn_al_tt_1 }\end{array}$ \\
\hline El rebozo de Soledad & $\begin{array}{l}1952 \\
\text { Roberto Gavaldón } \\
\text { México }\end{array}$ & $\begin{array}{l}\text { https://www.imdb.com/title/ } \\
\text { tt0132464/?ref_=fn_al_tt_1 }\end{array}$ \\
\hline El río y la muerte & $\begin{array}{l}1955 \\
\text { México } \\
\text { Luis Buñuel }\end{array}$ & $\begin{array}{l}\text { https://www.imdb.com/title/ } \\
\text { tt0047435/?ref_=fn_al_tt_1 }\end{array}$ \\
\hline En el paraíso no existe el dolor (SIDA) & $\begin{array}{l}1998 \\
\text { México } \\
\text { Víctor Saca }\end{array}$ & $\begin{array}{l}\text { https://www.imdb.com/title/ } \\
\text { tt0167136/?ref_=fn_al_tt_1 }\end{array}$ \\
\hline $\begin{array}{l}\text { En un motel nadie duerme (La cigarra no } \\
\text { es un bicho) }\end{array}$ & $\begin{array}{l}1989 \\
\text { México } \\
\text { Jesús Fragoso Montoya }\end{array}$ & $\begin{array}{l}\text { https://www.imdb.com/title/ } \\
\text { tt0380347/?ref_=fn_al_tt_1 }\end{array}$ \\
\hline La casa chica & $\begin{array}{l}1950 \\
\text { México } \\
\text { Roberto Gavaldón }\end{array}$ & $\begin{array}{l}\text { https://www.imdb.com/title/ } \\
\text { tt0041230/?ref_=fn_al_tt_1 }\end{array}$ \\
\hline
\end{tabular}

Rev. Med. Cine. 2021; 17 (3), 215-228 Ediciones Universidad de Salamanca / @@@ J. Med. Mov., 2021; 17 (3), $215-228$ [217] 


\section{EPIDEMIAS POR ENFERMEDADES INFECTO-CONTAGIOSAS EN EL CINE MEXICANO (1922-2019)}

ROCío BETZABEÉ GONZÁLEZ DE ARCE ARZAVE; JULIETA ELOISA GONZÁLEZ DE ARCE ARZAVE

\begin{tabular}{|c|c|c|}
\hline La dama de las camelias & $\begin{array}{l}1922 \\
\text { México } \\
\text { Carlos Stahl }\end{array}$ & $\begin{array}{l}\text { https://www.imdb.com/title/ } \\
\text { tt0218921/?ref_=fn_tt_tt_19 }\end{array}$ \\
\hline La dama de las camelias & $\begin{array}{l}1944 \\
\text { México } \\
\text { Gabriel Soria }\end{array}$ & $\begin{array}{l}\text { https://www.imdb.com/title/ } \\
\text { tt0036738/?ref_=fn_al_tt_1 }\end{array}$ \\
\hline La isla de los hombres solos & $\begin{array}{l}1974 \\
\text { México } \\
\text { René Cardona }\end{array}$ & $\begin{array}{l}\text { https://www.imdb.com/title/ } \\
\text { tt0327966/?ref_=fn_al_tt_1 }\end{array}$ \\
\hline Los insólitos peces gato & $\begin{array}{l}2013 \\
\text { México } \\
\text { Claudia Sainte-Luce } \\
\end{array}$ & $\begin{array}{l}\text { https://www.imdb.com/title/ } \\
\text { tt2414046/?ref_=fn_al_tt_1 }\end{array}$ \\
\hline Les orgueilleux (Los orgullosos) & $\begin{array}{l}1954 \\
\text { Francia, México } \\
\text { Yves Allégret y Rafael E. Portas }\end{array}$ & $\begin{array}{l}\text { https://www.imdb.com/title/ } \\
\text { tt0046149/?ref_=fn_al_tt_1 }\end{array}$ \\
\hline Los pobres van al cielo & $\begin{array}{l}1951 \\
\text { México } \\
\text { Jaime Salvador }\end{array}$ & $\begin{array}{l}\text { https://www.imdb.com/title/ } \\
\text { tt0043926/?ref_=fn_al_tt_1 }\end{array}$ \\
\hline Marejada & $\begin{array}{l}1952 \\
\text { México } \\
\text { Carlos Toussaint }\end{array}$ & $\begin{array}{l}\text { https://www.imdb.com/title/ } \\
\text { tt0268441/?ref_=fn_al_tt_1 }\end{array}$ \\
\hline María Candelaria (Xochimilco) & $\begin{array}{l}1944 \\
\text { México } \\
\text { Emilio Fernández }\end{array}$ & $\begin{array}{l}\text { https://www.imdb.com/title/ } \\
\text { tt0037054/?ref_=fn_al_tt_1 }\end{array}$ \\
\hline Mulata & $\begin{array}{l}1954 \\
\text { México } \\
\text { Gilberto Martínez Solares }\end{array}$ & $\begin{array}{l}\text { https://www.imdb.com/title/ } \\
\text { tt0046103/?ref_=fn_al_tt_1 }\end{array}$ \\
\hline Naná & $\begin{array}{l}1944 \\
\text { México } \\
\text { Celestino Gorostiza }\end{array}$ & $\begin{array}{l}\text { https://www.imdb.com/title/ } \\
\text { tt0036193/?ref_=fn_tt_tt_4 }\end{array}$ \\
\hline Naná & $\begin{array}{l}1985 \\
\text { México } \\
\text { Rafael Baledón, José Bolaños e } \\
\text { Irma Serrano }\end{array}$ & $\begin{array}{l}\text { https://www.imdb.com/title/ } \\
\text { tt0089667/?ref_=fn_al_tt_1 }\end{array}$ \\
\hline Nazarín & $\begin{array}{l}1959 \\
\text { México } \\
\text { Luis Buñuel }\end{array}$ & $\begin{array}{l}\text { https://www.imdb.com/title/ } \\
\text { tt0051983/?ref_=nv_sr_srsg_0 }\end{array}$ \\
\hline Ofrenda & $\begin{array}{l}1954 \\
\text { México } \\
\text { Francisco Reiguera }\end{array}$ & $\begin{array}{l}\text { https://www.imdb.com/title/ } \\
\text { tt0269653/?ref_=fn_al_tt_1 }\end{array}$ \\
\hline Pueblito & $\begin{array}{l}1962 \\
\text { México } \\
\text { Emilio Fernández }\end{array}$ & $\begin{array}{l}\text { https://www.imdb.com/title/ } \\
\text { tt0055337/?ref_=fn_al_tt_1 }\end{array}$ \\
\hline
\end{tabular}




\section{EPIDEMIAS POR ENFERMEDADES INFECTO-CONTAGIOSAS EN EL CINE MEXICANO \\ (1922-2019)}

Rocío BETZABEÉ gONZÁleZ de ARCE ARZAVE; JULIETA ELOISA GONZÁLEZ DE ARCE ARZAVE

\begin{tabular}{|c|c|c|}
\hline Río Escondido & $\begin{array}{l}1948 \\
\text { México } \\
\text { Emilio Fernández }\end{array}$ & $\begin{array}{l}\text { https://www.imdb.com/title/ } \\
\text { tt0039793/?ref_=fn_al_tt_1 }\end{array}$ \\
\hline S.I.D.A. Síndrome de muerte & $\begin{array}{l}1994 \\
\text { México } \\
\text { Paco del Toro }\end{array}$ & $\begin{array}{l}\text { https://www.imdb.com/title/ } \\
\text { tt0244770/?ref_=fn_al_tt_1 }\end{array}$ \\
\hline Satánico Pandemónium (La sexorcista) & $\begin{array}{l}1975 \\
\text { México } \\
\text { Gilberto Martínez Solares }\end{array}$ & $\begin{array}{l}\text { https://www.imdb.com/title/ } \\
\text { tt0070636/?ref_=fn_tt_tt_1 }\end{array}$ \\
\hline Seis días para morir & $\begin{array}{l}1967 \\
\text { México } \\
\text { Emilio Gómez Muriel }\end{array}$ & $\begin{array}{l}\text { https://www.imdb.com/title/ } \\
\text { tt0180136/?ref_=fn_tt_tt_1 }\end{array}$ \\
\hline Sólo con tu pareja & $\begin{array}{l}1992 \\
\text { México } \\
\text { Alfonso Cuarón }\end{array}$ & $\begin{array}{l}\text { https://www.imdb.com/title/ } \\
\text { tt0102958/?ref_=fn_tt_tt_1 }\end{array}$ \\
\hline Tiburoneros & $\begin{array}{l}1963 \\
\text { México } \\
\text { Luis Alcoriza }\end{array}$ & $\begin{array}{l}\text { https://www.imdb.com/title/ } \\
\text { tt0056584/?ref_=fn_al_tt_1 }\end{array}$ \\
\hline Todos son mis hijos & $\begin{array}{l}1951 \\
\text { México } \\
\text { Roberto Rodríguez }\end{array}$ & $\begin{array}{l}\text { https://www.imdb.com/title/ } \\
\text { tt0227664/?ref_=fn_al_tt_2 }\end{array}$ \\
\hline ¡Vámonos con Pancho Villa! & $\begin{array}{l}1936 \\
\text { México } \\
\text { Fernando de Fuentes }\end{array}$ & $\begin{array}{l}\text { https://www.imdb.com/title/ } \\
\text { tt0027240/?ref_=fn_al_tt_1 }\end{array}$ \\
\hline
\end{tabular}

enfermedad aparece como alegoría de un sistema de poder ilegítimo e injusto que enferma el tejido social de una comunidad, situación que denunciará insistentemente el melodrama rural mexicano.

\section{Viruela}

La viruela es otra enfermedad infecto-contagiosa que aparece con frecuencia en las películas mexicanas. Ocasionada por el virus variola, la viruela se caracteriza, además de por producir fiebres, vómito y dolores de cabeza, por ocasionar lesiones cutáneas en el cuerpo ${ }^{3}$. La película ¡Vámonos con Pancho Villa! (1936) de Fernando de Fuentes muestra con esta sintomatología a El Becerrillo, un fiel escolta del general revolucionario Francisco Villa, quien enferma de viruela en plena campaña. La película, adaptación de la novela del mismo nombre de Rafael F. Muñoz, presenta el dilema de Villa, quien queriendo evitar que la enfermedad se extienda por la tropa, ordena que el muchacho sea asesinado y que sus cosas y su cuerpo sean incinerados. La película caricaturiza a Villa y a sus subalternos presentándolos como hombres cobardes, quienes aterrados ante la posibilidad de un contagio, son capaces de llegar al crimen y traicionar los valores del movimiento revolucionario.

Dos frases de Tiburcio, el amigo de El Becerrillo a quien se le encarga dar muerte al joven enfermo, resumen el imaginario que vincula el miedo a la enfermedad con la cobardía antipatriótica y la traición a las causas de la Revolución Mexicana. La primera corresponde a la respuesta que Tiburcio da a sus superiores cuando le ordenan ultimar a su amigo: "¿Quemarlo, quemarlo

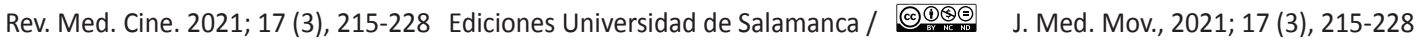




\section{EPIDEMIAS POR ENFERMEDADES INFECTO-CONTAGIOSAS EN EL CINE MEXICANO (1922-2019)}

ROCío BETZABEÉ GONZÁLEZ DE ARCE ARZAVE; JULIETA ELOISA GONZÁLEZ DE ARCE ARZAVE

vivo? ¿Pero se han vuelto ustedes locos? ¿Este es el pago a un soldado de la Revolución? ¿Es un ejército de hombres o una tropa de perros?" La segunda es lo que les dice a los soldados cuando se alejan de él temerosos de contagiarse: "iMugrosos, como si fueran a vivir cien años!". Ambas frases contienen la idea de que la hombría y el patriotismo implican, necesariamente, no tener miedo ni a la enfermedad ni a la muerte. ¿Será posible que esta idea esté aún presente en el imaginario nacional y que explique, aunque sea en parte, la reticencia de una parte de la población mexicana durante la actual pandemia de COVID-19 a guardar sana distancia, permanecer en casa y usar mascarilla?

La viruela, como la tuberculosis, aparece como castigo moralizador y expiatorio en las dos versiones de Naná producidas en México. En la primera, Naná (1944) de Celestino Gorostiza, el hijo de la protagonista adquiere la enfermedad y muere; mientras que, en la segunda, Naná (1985) de Rafael Baledón, José Bolaños e Irma Serrano, también ella se contagia y pierde la vida. La viruela como castigo divino y prueba para la fe del protagonista aparece en Nazarín (1959) de Luis Buñuel, adaptación de la novela homónima de Benito Pérez Galdós sobre un sacerdote venerado por tener, supuestamente, el don de sanar a los enfermos (Foto 1).

Finalmente, en Río Escondido (1948) de Emilio Fernández un médico enviado personalmente por el presidente de la República a un pueblo asolado por un cacique que acapara el agua y somete violentamente a los pobladores, emprende la vacunación de todos los lugareños cuando se desata un brote de viruela. Los esfuerzos del médico -y de la maestra rural- logran evitar las trágicas consecuencias de la epidemia y le salvan la vida al cacique, alegoría de la enfermedad (poder autoritario, ilimitado y corruptor) que aqueja al pueblo. La secuencia cinematográfica en la que se muestra el combate heroico contra la enfermedad (vacunación masiva) a través de la educación y la ciencia (la maestra y el médico rural que inmunizan a la población) alegoriza el avance, hasta los rincones más atrasados del país, del progreso modernizador abanderado por los gobiernos posrevolucionarios de la época. La enfermedad y su combate son en esta película alegoría política.

\section{Sarampión}

Producido por un miembro del género Morbillivirus, el sarampión está "considerado entre las infecciones más contagiosas de la infancia"4. Ésta virosis produce un "exantema que se inicia habitualmente en la cara, y de forma centrifuga se disemina a tronco y extremidades"4. El sarampión aparece al menos en una película mexicana: la ya mencionada El rebozo de Soledad (1952) de Roberto Gavaldón. En este filme, un médico capitalino llega a la iglesia del pueblo al que ha sido asignado buscando a un niño cuyo hermano ha contraído la enfermedad. El médico pretende evitar el brote epidémico poniendo al chico en cuarentena, pero el sacerdote se lo impide tras sostener con él, en el comedor de la parroquia, el siguiente diálogo:

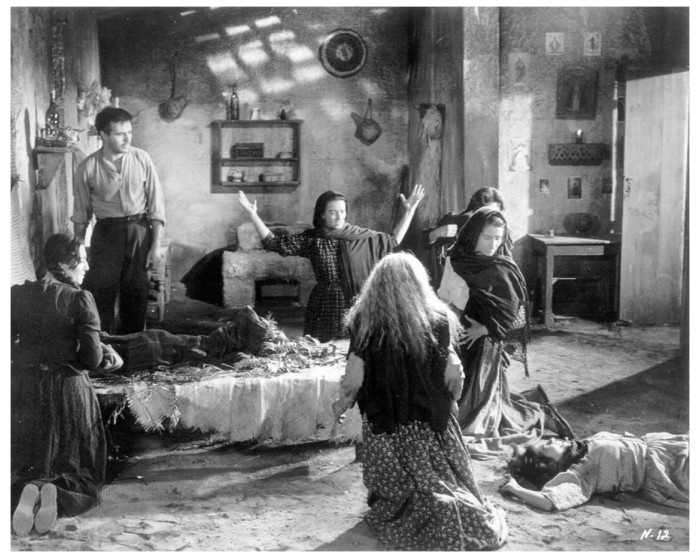

Foto 1. Las mujeres ruegan a Nazarín que sane a un enfermo en la cinta Nazarín (1951) de Luis Buñuel. 


\section{EPIDEMIAS POR ENFERMEDADES INFECTO-CONTAGIOSAS EN EL CINE MEXICANO \\ (1922-2019)}

ROCío BETZABEÉ GONZÁlEZ DE ARCE ARZAVE; JULIETA ELOISA GONZÁLEZ DE ARCE ARZAVE

Sacerdote: "Ahí tienes a tu agente transmisor de enfermedades. ¿No te da gusto verlo comer así?"

Doctor: "A mí lo que me interesa es que no contagie a sus compañeros".

Sacerdote: "Pues a mi lo que me interesa es que coma. En su casa son muy pobres y si lo despacho ahora solo lograré privarlo de su café con leche y su pan. De sarampión no se mueren los niños, pero tengo entendido que de hambre se mueren bastantes cada año." Doctor: "Desgraciadamente así es. Tiene razón, padre Juan. Perdóneme".

El sarampión sirve en esta secuencia para construir la alegoría del hambre, y por tanto de la pobreza, como una epidemia no infecciosa, pero mucho más mortífera que las enfermedades infecto-contagiosas.

\section{Paludismo}

El paludismo es una protozoosis ocasionada por especies del género Plasmodium que infectan al ser humano a través de la picadura de las hembras de los mosquitos del género anófeles 5 . Muy probablemente, es por esta razón que en el cine mexicano el paludismo a menudo aparece como una enfermedad que ataca principalmente a los hombres, y que se asocia alegóricamente, con el desbordamiento de las pasiones masculinas en los exuberantes ambientes tropicales que se relacionan con lo femenino. En una secuencia de María Candelaria (Xochimilco) (1944) de Emilio Fernández, por ejemplo, un par de médicos llegan al poblado lacustre de Xochimilco con un lote de quinina, alcaloide antipalúdico, y al entregarlo a don Damián, el tendero y jefe del pueblo, para que se reparta entre la población como medida profiláctica, sostienen el siguiente diálogo:

Doctor: "¿Se han dado nuevos casos de paludismo?"
Don Damián: "Pues algunos doctor. Ya van varios que se petatean. Pero qué raro que sea la hembra del mosquito la que pique y enferme, ¿verdad?"

Doctor: "¿Raro? ¿Por qué? ¿No dicen que todos los males nos vienen de las hembras?"

El resto de la película gira precisamente en torno al conflicto entre dos hombres por una mujer, María Candelaria. Don Damián enojado porque la joven lo ha rechazado y es novia de Lorenzo Rafael, les niega a ambos la quinina. Entonces, María Candelaria enferma gravemente de paludismo y Lorenzo Rafael, desesperado, roba el medicamento de la tienda de Don Damián. María Candelaria se recupera, pero Lorenzo Rafael es hecho prisionero. La película termina trágicamente con la muerte de ella y el suicido de él.

Como puede verse, el paludismo aparece a menudo como alegoría de la injusticia social o la explotación laboral. Así ocurre en películas como Todos son mis hijos (1951) de Roberto Rodríguez, en el que el joven Juan contrae paludismo en un campo chiclero; Tiburoneros (1963) de Luis Alcoriza, donde el palúdico pescador Rubén debe robar porque no puede trabajar para mantener a su familia; y en La isla de los hombres solos (1974) de René Cardona, adaptación cinematográfica de la novela del mismo nombre de José León Sánchez, que denuncia los maltratos sufridos por los prisioneros del penal de la Isla San Lucas, muchos de los cuales mueren a causa del paludismo.

\section{Influenza española}

Ocasionada por un subtipo del virus $A$ (H1N1), la peste roja, como se le conoció en México, estalló en los estados del norte en octubre de 1918 mientras el país se encontraba aún inmerso en el conflicto revolucionario iniciado en $1910^{6}$. El virus de la influenza española se extendió rápidamente por toda la República Mexicana, atacando el tejido pulmonar de los infectados, 
quienes sufrían hemorragias y cuadros de neumonía que en muchos casos resultaban fatales.

Las consecuencias en la población y el impacto devastador que tuvo la gripe española en las tropas revolucionarias mexicanas se abordan en Del odio nace el amor (1951) de Emilio Fernández, versión para el mercado norteamericano de la película Enamorada (1946) de Emilio Fernández. Conocida también con los títulos The Torch o Beloved, la película incluye toda una secuencia, inexistente en Enamorada, en que se muestra la pandemia de influenza extendiéndose por las tropas del general José Juan Reyes, quien se ve obligado a la retirada frente al Ejercito Federal a causa del brote epidémico. La injusticia social que dio pie a la Revolución es en esta película alegorizada por la enfermedad.

Siguiendo esta lógica alegórica, la película presenta al general revolucionario Reyes irremediablemente enamorado de María Dolores Peñafiel, una rica joven poblana, quien lo rechaza continuamente. En el contexto de este melodrama, la lucha revolucionaria de los pobres frente a los ricos es alegorizada por los continuos intentos del general por conquistar a la mujer aristócrata. La influenza española, por su parte, alegoriza la momentánea derrota del movimiento revolucionario, que tendrá una nueva esperanza cuando María Dolores (alegoría de las clases altas) decida cancelar su boda con un doctor estadounidense (alegórico de los intereses extranjeros) y seguir al general (alegórico de las clases populares) en su lucha.

\section{Oncocercosis}

La oncocercosis, también conocida como ceguera de los ríos, es el centro de la situación dramática que da pie al conflicto en La casa chica (1950) de Roberto Gavaldón, filme en que el médico Fernando Mendoza y su asistente Amalia Estrada emprenden la lucha heroica contra esta filariasis en una población pobre y apartada de México. Producida por el nemátodo Onchocerca volvulus, que es inoculado por un insecto díptero del género Simulium, la oncocercosis se caracteriza por "nódulos en la piel, lesiones dérmicas y lesiones oculares" que pueden derivar en ceguera en los casos más graves ${ }^{7}$.

En la película, Fernando y Amalia comienzan a atender a los enfermos y a practicar cirugías para evitar que los habitantes del pueblo queden ciegos. El éxito que consiguen se ve opacado porque, aunque enamorados, no pueden casarse pues él está comprometido con una mujer de la alta sociedad que finge un suicidio para retenerlo. El combate a la oncocercosis aparece así como un recurso dramático que enfatiza el sacrificio del deseo y la renuncia a la realización personal en aras del deber. La enfermedad resulta pues alegórica de la opresión social ejercida sobre los protagonistas quienes curan a cientos de la ceguera pero, paradójicamente, deben mantener su relación extramarital oculta, fuera del alcance del ojo vigilante y censor de la sociedad.

\section{Poliomielitis}

La poliomielitis es una enfermedad altamente infecciosa causada por un grupo de enterovirus humanos que afecta al sistema nervioso central causando parálisis flácida en distintos grados ${ }^{8}$. En el cine mexicano aparece por lo menos en tres películas. La primera, Los pobres van al cielo (1951) de Jaime Salvador, cuenta la historia de los huérfanos Lupe y Andrés. Ella enferma de poliomielitis y queda paralizada de las piernas; mientras que su hermano pasa un tiempo en el reformatorio acusado injustamente de asesinato. La enfermedad aparece aquí como una prueba de la fibra moral de Lupe, quien se purifica a través del sufrimiento. Se trata de una alegoría cristiana que culmina con el mensaje de que la enfermedad es un medio para reafirmar la fe y alcanzar la salvación eterna.

También como prueba moral y alegoría cristiana de sacrificio personal aparece la poliomielitis en Ofrenda (1954) de Francisco Reiguera, 


\section{EPIDEMIAS POR ENFERMEDADES INFECTO-CONTAGIOSAS EN EL CINE MEXICANO \\ (1922-2019)}

RoCío BETZABEÉ gONZÁlEZ DE ARCE ARZAVE; JULIETA ELOISA GONZÁLEZ DE ARCE ARZAVE

cinta en la que Ofelia, después de ser operada exitosamente de los ojos por el médico Enrique, se dedica a buscar un tratamiento para la poliomielitis, enfermedad que aqueja a la hija del doctor. Al experimentar en ella misma un suero, Ofelia queda paralizada y se resigna a vivir sola, ofrendando así su vida para la consecución del avance médico.

En El río y la muerte (1955) de Luis Buñuel, adaptación de la novela Muro blanco en roca negra de Miguel Álvarez Acosta, el joven médico Gerardo contrae poliomielitis y es colocado en un "pulmón de acero", una cámara de vacío o de presión negativa (VPN) diseñada en 1928 por el ingeniero Philip Drinker y por el fisiólogo Agussiz Shaw que ofrecía soporte ventilatorio a los pacientes afectados por la poliomielitis ${ }^{9}$. En la película, la parálisis que sufre Gerardo resulta una alegoría de la decisión del joven de no continuar con el ciclo de venganza que ha llevado a la muerte a la mayoría de los hombres de su pueblo natal (Foto 2).

\section{Fiebres negras}

Las fiebres negras son causadas por más de 20 especies de parásitos protozoarios del género Leishmania que tienen como vector a las moscas de arena de los géneros Phlebotomus y Lutzomyia. Estas leishmaniasis pueden ocasionar úlceras cutáneas y nódulos, afectar las membranas mucosas o dañar órganos internos condicionando un riesgo para la vida ${ }^{10}$.

Las fiebres negras son el centro dramático de la película As negro (1954) de Fernando Méndez, filme que narra la historia de los hermanos gemelos, Julio, quien estudia medicina y se especializa en las fiebres negras y, Germán, quien para pagar los estudios de su hermano se convierte en un delincuente. Cuando Julio es asesinado por error por los enemigos de su hermano, éste asume su identidad y continúa sus investigaciones. Germán prueba en sí mismo la droga experimental contra la leishmaniasis que había elaborado

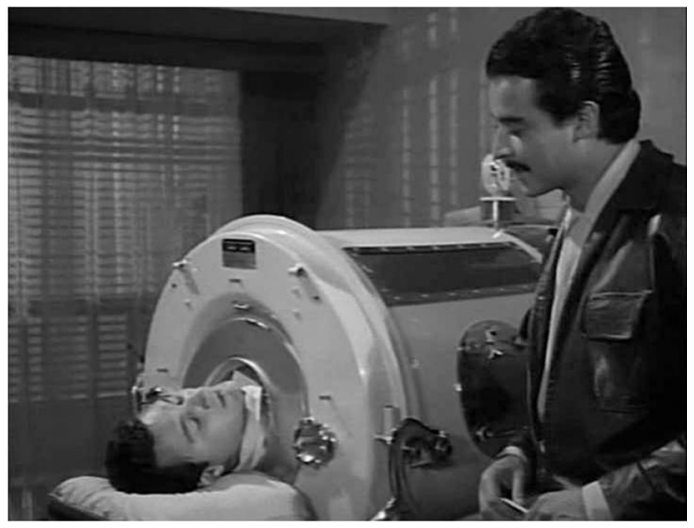

Foto 2. Rómulo Menchaca visita a Gerardo Anguiano, quien permanece en un pulmón de acero que le ayuda a respirar, pues sufre las secuelas de la poliomielitis en El río y la muerte (1955) de Luis Buñuel.

su hermano $y$, aunque con ello logra determinar las dosis adecuadas para un tratamiento, muere como consecuencia de esta experimentación. No resulta extraño que la droga produzca la muerte de Germán pues, en tanto que criminal, el es lo que enferma a la sociedad. De este modo, las fiebres negras constituyen, en la cinta, el vehículo de redención de su vida delincuencial y la posibilidad de que la sociedad pueda sanar.

\section{Difteria}

La difteria o garrotillo es una bacteriosis potencialmente fatal causada principalmente por Corynebacterium diphtheriae, C. ulcerans o C. pseudotuberculosis cuya toxigenicidad produce faringitis seudomembranosa que llega a ocasionar asfixia, lesiones en la piel y daños en los tejidos del miocardio, riñones y el sistema nervioso ${ }^{11}$.

En la ya citada El rebozo de soledad (1952) de Roberto Gavaldón, el médico Alberto, decepcionado porque la ignorancia y el abuso de poder no le permiten llevar salud a los habitantes de un pueblo apartado, decide renunciar y volver a 


\section{EPIDEMIAS POR ENFERMEDADES INFECTO-CONTAGIOSAS EN EL CINE MEXICANO \\ (1922-2019)}

ROCío BETZABEÉ GONZÁlEZ DE ARCE ARZAVE; JULIETA ELOISA GONZÁLEZ DE ARCE ARZAVE

la capital, pero estando en la estación del tren se encuentra a una mujer con un niño en brazos que apenas respira. De inmediato, Alberto le diagnostica difteria y le realiza una traqueotomía para evitar que muera asfixiado. La satisfacción de haberle salvado la vida al pequeño lo convence de que su misión es quedarse en el pueblo a ayudar a los enfermos. De nueva cuenta, la enfermedad es alegórica de la ignorancia de la población y de las condiciones de pobreza y de injusticia social a las que están sometidos, y que los gobiernos posrevolucionarios enfrentan con los conocimientos de la ciencia médica. Esta misma batalla alegórica es librada en Marejada (1952) de Carlos Toussaint por otro médico rural, quien debe enfrentarse a la oposición de los habitantes de una población costera y de la hierbera del lugar para contener un brote epidémico de difteria que arrasa con la vida de los niños de la comunidad.

\section{Peste negra}

La peste negra es una bacteriosis causada por Yersinia pestis. La enfermedad puede ser pulmonar o bubónica. En el primer caso, ocasiona cuadros neumónicos; mientras que, en el segundo, se caracteriza por una linfadenopatía (bubas) septicémica que suele ser fulminante ${ }^{12}$.

La peste negra aparece al menos en dos ocasiones en el cine mexicano. En Satánico Pandemónium (La sexorcista) (1975) de Gilberto Martínez Solares es la responsable de las alucinaciones eróticas y diabólicas de la monja de un convento, por lo que resulta alegoría de la posesión demoniaca. Por otro lado, en El año de la peste (1980) de Felipe Cazals, adaptación de la novela Diario del año de la peste de Daniel Defoe, el brote de peste negra se asocia a las condiciones de contaminación, hacinamiento y pobreza en que viven los habitantes de la ciudad de México (Foto 3). Así pues, si hasta antes de los años setenta del siglo XX las epidemias en el cine mexicano eran alegóricas del atraso rural, a partir de esta década se vuelven un problema urbano y alegorizan la podredumbre producto de la fracasada modernidad citadina.

\section{Fiebre tifoidea}

La fiebre tifoidea es una enfermedad ocasionada por la infección de la bacteria Salmonella typhi y su sintomatología se caracteriza por escalofríos, fiebre, sudores, cefalalgia, dolor lumbar, náuseas, vómitos, delirios y convulsiones ${ }^{13}$.

En Pueblito (1962) de Emilio Fernández, por otra parte, la tifoidea aparece de nuevo como alegoría del atraso rural y del caciquismo cuando, para salvar la vida de un niño con fiebre tifoidea, un ingeniero debe llevarlo en su motocicleta (alegoría de la tecnología moderna) hasta un hospital desafiando las objeciones del lugarteniente.

\section{Meningitis cerebroespinal epidémica}

La meningitis cerebroespinal epidémica es resultado de la complicación de un proceso infecciosos ocasionado por un agente ya sea viral, fúngico, bacteriano o parasitario. Dicho agente produce la inflamación de las meninges, esto es, de las membranas que protegen el cerebro y la médula espinal ${ }^{14}$.

En la coproducción franco-mexicana Los orgullosos (1953) de Yves Allégret y Rafael E. Portas, es un ciudadano francés el que enferma al llegar a un pueblo costero de México. La enfermedad infecciosa del extranjero se complica y fallece a causa de una meningitis cerebroespinal epidémica, dejando a su viuda varada en el pueblo. El médico de la comunidad, con ayuda de un médico francés dipsómano que lleva años viviendo en el lugar, comienza a atender a los enfermos. La viuda se enamora del médico francés y el decreto de la cuarentena para el pueblo le permite quedarse con él, quien deja de beber para poder atender a los contagiados. La enfermedad es para la pareja alegoría paradisiaca y utópica que se hace posible con la cuarentena, aunque al principio de la cinta resulta también 


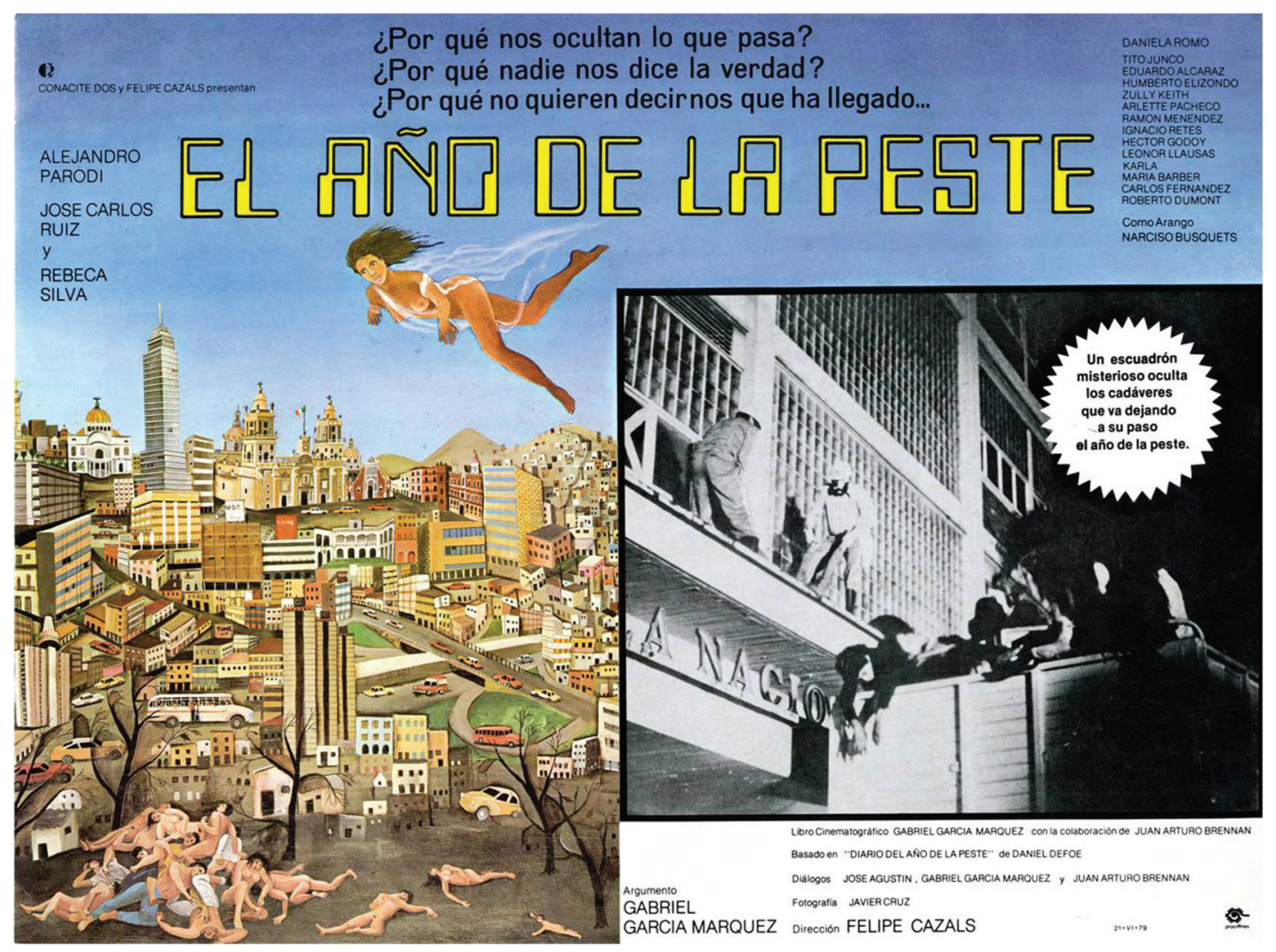

Foto 3. Cartel publicitario de la película El año de la peste (1980) de Felipe Cazals.

alegoría xenofóbica, pues es un otro extranjero quien introduce la enfermedad a la comunidad.

Destaca de esta película la secuencia en que los médicos y la viuda son vacunados con una inyección intrarraquídea, lo que seguramente constituye una confusión con la técnica de punción lumbar que se utiliza como prueba diagnóstica para determinar el agente infeccioso etiológico de la meningitis.

\section{Rabia}

La rabia o hidrofobia es ocasionada por un virus del género Lyssavirus que afecta el sistema nervioso ocasionando primero fiebre, cefalea, malestar general, náuseas y vómitos. La enfermedad progresa hasta una fase neurológica aguda que en prácticamente casi todos los casos derivan en un estado de coma y finalmente en la muerte. Todos los mamíferos de sangre caliente son susceptibles de contraer la enfermedad, pero en sus ciclos urbanos son los perros el principal vector $^{15}$.

En la película mexicano-estadunidense $E I$ mal (The Rage) (1967) de Gilberto Gazcón un médico atormentado por no haber podido salvar a su esposa cuando iba a dar a luz se contagia de rabia al atender a un hombre que ha contraído la enfermedad después de haber sido mordido por un perro. Estando en un campamento en medio del desierto, el médico debe viajar a la ciudad 


\section{EPIDEMIAS POR ENFERMEDADES INFECTO-CONTAGIOSAS EN EL CINE MEXICANO (1922-2019)}

ROCíO BETZABEÉ GONZÁLEZ DE ARCE ARZAVE; JULIETA ELOISA GONZÁLEZ DE ARCE ARZAVE

para conseguir vacunarse. La enfermedad es en esta película metáfora de la culpa que aflige al médico, y el viaje que emprende para encontrar la vacuna resulta una alegoría de la travesía personal del personaje para liberarse de su pasado traumático y poder rehacer su vida.

En Seis días para morir (1967) de Emilio Gómez Muriel, un periodista busca en la ciudad de México a cuatro niños que han sido mordidos por un perro rabioso para que sean vacunados antes de que desarrollen la enfermedad. A través de notas con tintes amarillistas, el periodista logra encontrar a tres de los infantes, pero no logra salvar al último, quien resulta ser su hijo (Foto 4). La rabia es en esta película metáfora no solo de la ignorancia, sino alegoría moralizante respecto al periodismo tendencioso y alarmista que contribuye a lo que, en tiempos recientes, se ha dado en llamar infodemia, para referirse al "exceso de información, en gran parte falsa, sobre un problema, que dificulta su solución"16.

\section{Infección por VIH}

El virus de la inmunodeficiencia humana (VIH) se transmite por el uso de sangre y hemoderivados contaminados, de la madre al feto o por vía sexual. Este retrovirus ataca el sistema inmunológico de las personas infectadas, lo que puede derivar en la aparición de afecciones neoplásicas o infecciones oportunistas que, de manera crónica, llegan a comprometer la vida. Al conjunto de síntomas producidos por el $\mathrm{VIH}$ se le denominó Síndrome de Inmunodeficiencia Adquirida (SIDA $)^{17}$. Los primeros casos de esta enfermedad se detectaron en Estados Unidos en 1981 y en México en 1983. Los prejuicios morales, la desinformación y la discriminación frenaron las medidas para contener el avance de la epidemia en nuestro país. No fue sino hasta 1986 cuando se creó el Consejo Nacional para la Prevención del SIDA (CONASIDA) ${ }^{18}$. El tema fue tocado por el cine mexicano en una película producida en

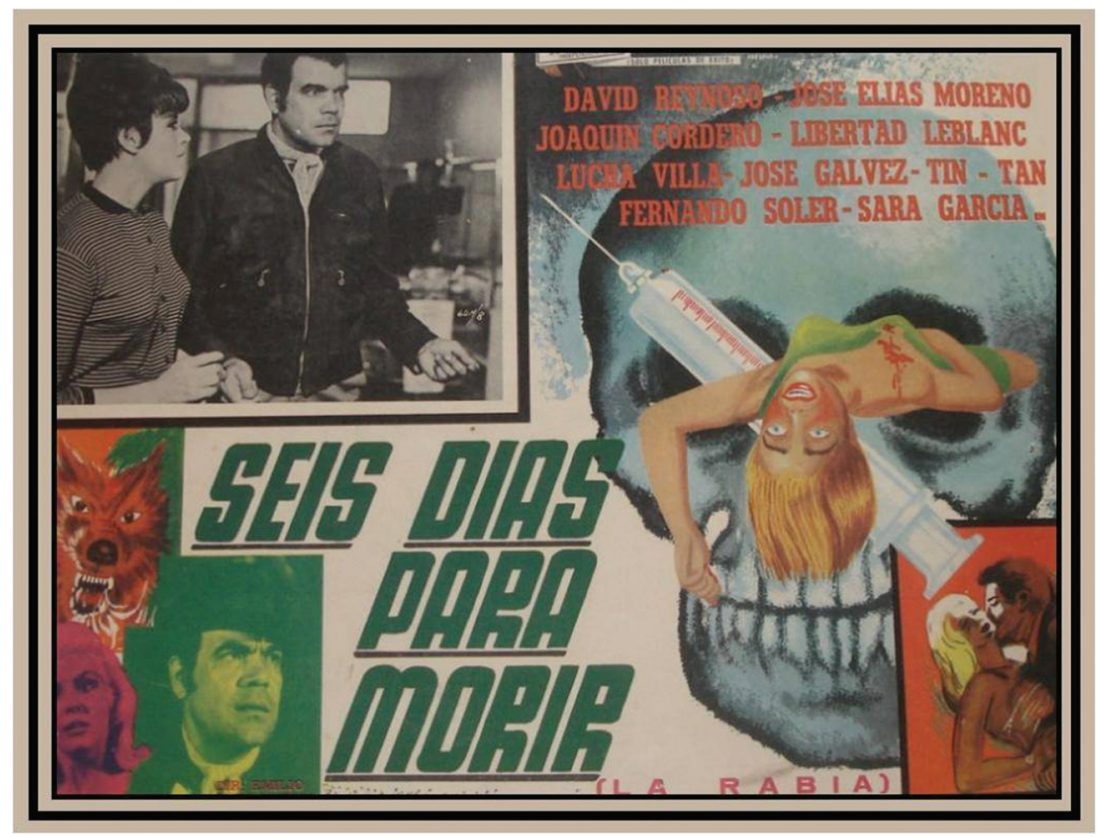

Foto 4. Cartel publicitario de la película Seis días para morir (1967) de Emilio Gómez Muriel.

Rev. Med. Cine. 2021; 17 (3), 215-228 Ediciones Universidad de Salamanca / @@@ J. Med. Mov., 2021; 17 (3), $215-228$ [226] 
1987 pero estrenada dos años después, Casos de Alarma 1 (SIDA) (1989) de Benjamín Escamilla, que en tono de nota roja utiliza la enfermedad para hacer una condena moral de la homosexualidad y la promiscuidad (Foto 5). A esta cinta seguirán varias otras en que la infección por VIH es alegoría homofóbica y moralizante. Es el caso de Amor que mata (1994) de Valentín Trujillo, S.I.D.A. Síndrome de muerte (1994) de Paco del Toro y En el paraíso no existe el dolor (SIDA) (1998) de Víctor Saca.

Algunas comedias de enredos como Bienvenido-Welcome (1995) de Gabriel Retes, En un motel nadie duerme (La cigarra no es un bicho) (1989) de Jesús Fragoso Montoya y Solo con tu pareja (1992) de Alfonso Cuarón utilizan como conflicto detonante de sus tramas la supuesta infección por VIH de alguno de los miembros de la comunidad. En estas películas, el diagnóstico resulta finalmente un falso positivo, pero la enfermedad es el recurso que devela la verdadera condición moral de los personajes. Es posible decir que estos filmes son alegóricos de la negación que durante años se vivió en México en torno a la epidemia por VIH. De hecho, tendrían que pasar dos décadas a partir de la detección de los primeros casos para que el cine mexicano comenzara a hacer un tratamiento más maduro, no moralizador ni prejuicioso de esta enfermedad en películas como Los insólitos peces gato (2013) de Claudia Sainte-Luce.

\section{Gripe viral indeterminada}

En 2019 se estrenó en México El hubiera si existe de Luis Eduardo Reyes, película en que la protagonista recibe la visita, desde el futuro, de su hermano, quien le advierte que debe terminar con su novio porque al besarlo provocará en el 2020 la mutación de un virus que provocará una pandemia gripal. Probablemente inspirada en el brote de influenza A (H1N1) de 2009, la secuencia ha circulado por internet como una premonición cinematográfica de la actual epidemia por covid.

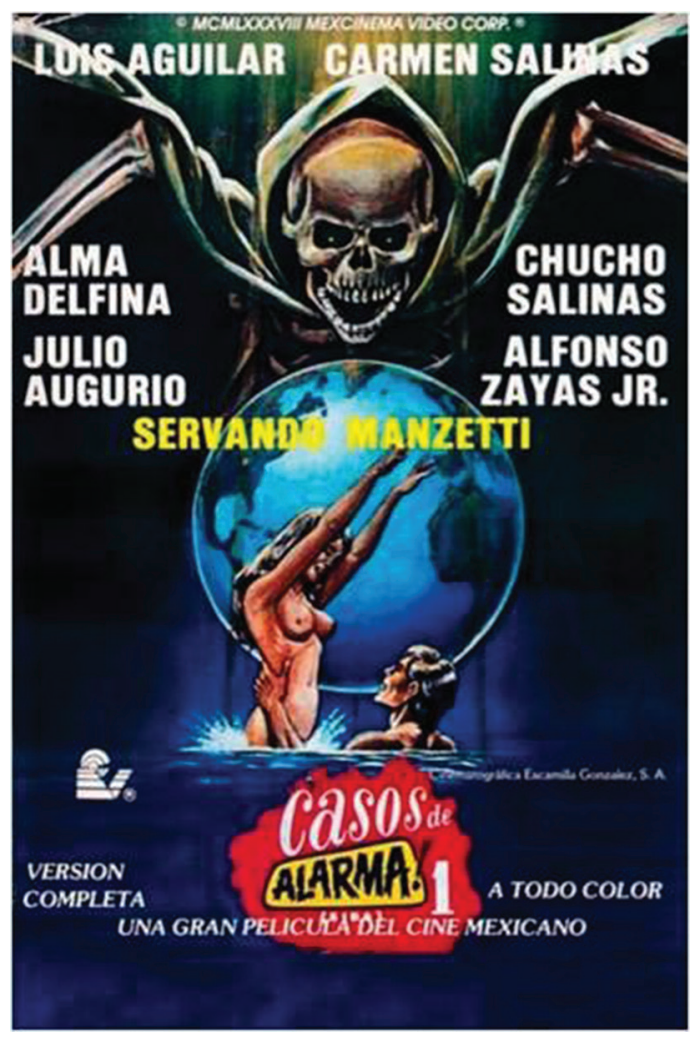

Foto 5. Cartel publicitario de la película Casos de Alarma 1 (SIDA) (1989) de Benjamín Escamilla.

Más allá de esto, esta película nos lleva a preguntarnos cómo abordará el cine mexicano la epidemia que actualmente nos aqueja y de qué resultará alegórica la COVID-19 en la pantalla grande.

\section{Conclusiones}

Si bien desde la segunda década del siglo veinte las instituciones de enseñanza y de salud del Estado Mexicano han producido cintas educativas, ya sea documentales o de ficción, como parte de campañas para el combate y la erradicación de enfermedades infecto-contagiosas; como hemos visto a lo largo del recorrido fílmico aquí hecho, el cine de corrida comercial mexicano ha 


\section{EPIDEMIAS POR ENFERMEDADES INFECTO-CONTAGIOSAS EN EL CINE MEXICANO (1922-2019)}

ROCío BETZABEÉ GONZÁLEZ DE ARCE ARZAVE; JULIETA ELOISA GONZÁLEZ DE ARCE ARZAVE

también tratado de manera recurrente el tema de las epidemias infecto-contagiosas. De hecho, es posible que, no solo por su difusión masiva sino por su gran capacidad de seducción narrativa, las películas comerciales hayan tenido un mayor impacto educativo en la sociedad mexicana que los materiales elaborados con fines expresamente instructivos. Precisamente por la fuerza didáctica que tiene el cine es que resulta importante analizar, como aquí lo hemos hecho, los sistemas de metáforas que los filmes construyen alrededor de estas enfermedades. No solo porque ello nos permite entender, por ejemplo, los imaginarios que impiden o favorecen el control de brotes epidémicos infecciosos o aprender de las experiencias epidémicas pasadas; sino porque, además, como hemos visto, las enfermedades alegorizan las ansiedades de nuestras sociedades a lo largo de su historia y, en ese sentido, su estudio posibilita reflexionar sobre nosotros mismos.

\section{Referencias}

1. Sontag S. La enfermedad y sus Metáforas; El sida y sus Metáforas. Madrid: Taurus; 1996.

2. Garza-Velasco R, Ávila-de Jesús J, Perea-Mejía LM. Tuberculosis pulmonar: la epidemia mundial continúa y la enseñanza de este tema resulta crucial y compleja. Educ. Quim. 2017;28(1):38-43.

3. Coto CE. La viruela: peste del pasado, amenaza del presente. Química Viva. 2002;1(1):5-14.

4. Delpiano L, Astroza L, Toro J. Sarampión: la enfermedad, epidemiología, historia y los programas de vacunación en Chile. Rev. Chil. Infectol. 2015;32(4):417-29.

5. Betanzos Reyes AF. La malaria en México: Progresos y desafíos hacia su eliminación. Bol. Med. Hosp. Infant Mex. 2011;68(2):159-68.
6. Márquez Morfín L, Molina del Villar A. El otoño de 1918: las repercusiones de la pandemia de gripe en la ciudad de México. Desacatos. 2010;(32).121-44.

7. Zaragonazo JF, Rodríguez Martínez G. Oncocercosis. Medicina Integral. 2000;35(3):118-21.

8. González-Rubio R. La poliomielitis y su erradicación en México. Reto histórico de salud hecho realidad. Sal. Jal. 2018;5(1):49-51.

9. Romero-Ávila P, Márquez-Espinós C, Cabrera-Afonso JR. Historia de la ventilación mecánica. De la Antigüedad a Copenhague 1952. Rev. Med. Chile. 2020;148:822-30.

10. Urmeneta Roncal C. Leishmaniausus humana. Un problema de salud pública. NPunto. 2019;2(20):25-45.

11. Sharma NC, Efstratiou A, Mokrousov I, Mutreja A, Das B, Ramamurthy T. Diphtheria. Nat. Rev. Dis. Primers. 2019;5(81):1-18.

12. Pedroso Flaquet P. La peste, enfermedad infectocontagiosa reemergente. Rev. Cubana Med. Gen. Integr. 2010;26(2):360-75.

13. Flores-Espinosa J. Tifoidea en México. Análisis clínico de la epidemia de 1972. Gac. Med. Mex. 1973;106(1):11-36.

14. Floriani C. Meningitis cerebro-espinal epidémica. Rev. Med. Hondur. 1935;A5(10):685-93.

15. Frantchez V y Medina J. Rabia: 9,9\% mortal, 100\% prevenible. Rev. Méd. Urug. 2018;34(3):164-71.

16. RAE (@RAEinforma). 2020. La OMS ha acuñado el acrónimo «infodemia». Twitter 8 de abril de 2020. [Consultado el 31 de diciembre de 2020].

17. Lamotte Castillo JA. Infección por VIH/sida en el mundo actual. MEDISAN. 2014;18(7):993-1013.

18. Ponce de León S. El principio de la epidemia en México. Rev. Invest. Clín. 2004;56(2):124-25.

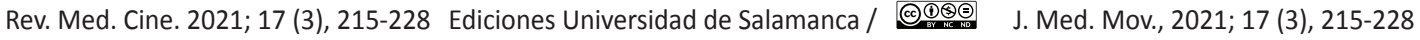
[ 228 ] 